\title{
ERRATA
}

\section{Characterization of Multidrug-Resistant Escherichia coli Isolates} Associated with Nosocomial Infections in Dogs

Susan Sanchez, M. A. McCrackin Stevenson, Charlene R. Hudson, Marie Maier, Tameka Buffington, Quyen Dam, and John J. Maurer

Athens Diagnostic Laboratory and the Departments of Medical Microbiology and Parasitology, Small Animal Medicine, and Avian Medicine, College of Veterinary Medicine, The University of Georgia,

and Agricultural Research Service, U.S. Department of Agriculture,

Russell Research Center, Athens, Georgia 30602

Volume 40, no. 10, p. 3586-3595, 2002. Page 3589, Table 2, column 8: Line 17 should read "280, 115 " and line 18 should be blank.

\section{Direct PCR Detection of Burkholderia cepacia Complex and Identification of Its Genomovars by Using Sputum as Source of DNA}

Pavel Dřevínek, ${ }^{1 *}$ Hana Hrbáčková, ${ }^{2}$ Ondřej Cinek, ${ }^{1}$ Jana Bartošová, ${ }^{1}$ Otakar Nyč ${ }^{2}$ Alexandr Nemec, ${ }^{3}$ and Petr Pohunek ${ }^{1}$

2nd Department of Pediatrics, 2nd Medical School of Charles University, ${ }^{1}$ Department of Medical Microbiology, Motol University Hospital, ${ }^{2}$ and National Institute of Public Health, ${ }^{3}$ Prague, Czech Republic

Volume 40, no. 9, p. 3485-3488. Page 3485: The byline should read as given above. 